INTERNATIONAL DESIGN CONFERENCE - DESIGN 2018

https://doi.org/10.21278/idc.2018.0454

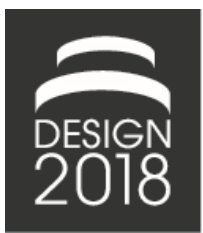

\title{
TOWARD A SUPPORTIVE ECO-INNOVATION PLATFORM BASED ON ECO-IDEATION STIMULATION MESO-MECHANISMS AND ECO-INNOVATION CASES
}

\author{
C. C. Pham, F. Vallet, B. Tyl, O. Pialot and B. Eynard
}

\begin{abstract}
This paper presents the ALIENNOR platform that is developed within French research project ALIENNOR to promote eco-innovation by providing different kinds of users with a rich base of ecoinnovation cases and seven eco-ideation stimulation meso-mechanisms (ESMs). With two main modules "Methodology" and "Community", the proposed platform focuses mainly on how to explore seven ESMs and the base of eco-innovation cases and how to facilitate the tagging process (associate one or many mechanisms to an eco-innovation case and vice versa) of experts.
\end{abstract}

Keywords: eco-innovation, sustainable design, design tools, eco-ideation stimulation mesomechanisms, eco-innovation platform

\section{Introduction}

The environmental consequences of manufacturing and mass consumption require a complete rethinking of how we design, produce and consume. More than ever, to remain sustainable, companies have to successfully develop and put into the market, products or services with strong environmental ambitions. Eco-innovation, the integration of environmental and social issues in innovation processes, increasingly gains a strong interest of the manufactural industry. Since the eco-innovation is still ambiguous for industrial practitioners, environmental and social gains obtained by applying ecoinnovation methods in design are limited.

Eco-ideation is an early phase of eco-innovation process, in which ideas with great potential for reducing environmental impact are generated (Bocken et al., 2011). Therefore, the eco-ideation is essential and takes place upstream the eco-innovation process (Tyl et al., 2016). Many eco-ideation tools and methods have been proposed such as Eco-Compass (Fussier and James, 1996), LiDS Wheel (Brezet, 1997), Value Mapping Tool (Bocken et al., 2013), EcoASIT (Tyl et al., 2014) and recently MIRAS (Real, 2015).

A part of the French research program ALIENNOR is to conduct an open eco-innovation platform that aims to promote the eco-innovation by providing different kinds of users (scientists, engineering designer experts, industrial practitioners, students) with a set of eco-ideation stimulation mesomechanisms (ESMs), eco-evaluation tools and a rich base of original eco-innovation cases. Seven ESMs (Tyl et al., 2017) are integrated into the ALIENNOR platform to help users to generate eco-innovative ideas in the early design phases of the eco-innovation process. The base of eco-innovation cases contains nearly 50 cases in development (from 300 to 500 cases in production) classified into different categories. In order to have an optimal exploration, all cases are well-structured and presented in a common form. Some eco-evaluation tools like voting mechanisms are used to label eco-innovation cases (associate each case with two or three main ESMs). 
After presenting some existing eco-ideation/ eco-innovation platforms in Section 2, the paper introduces in Section 3 the proposed ALIENNOR platform with a detailed description of two main modules, three scenarios and core functions. The paper ends at Section 4 with some conclusion and perspectives.

\section{Platforms promoting sustainability-related innovations}

Many ideation methods and tools are proposed. Among them, the "Theory of Inventive and Problem Solving", or so-called name TRIZ developed by G. Altshuller is the most well-known. Being an organized method for problem solving, TRIZ can be applied for eco-design thus it consists of different tools, which are applicable for idea generation (contradiction matrix, forty inventive principles, evolution patterns, ideality and trends of engineering system evolution) (Buzuku and Shnai, 2018). Many tools were proposed as results of the combination of TRIZ with other theories, such as Case Based Reasoning (CBR) (Yang and Chen, 2011) or Life Cycle Assessment (LCA) (Russo et al., 2011, 2015). Many platforms, based on these proposed ideation methods, have been developed to promote the ecoinnovation. Three main emphases are observed: methodological insights (Ecosmes.net (Buttol et al., 2012)), social network insights (Babele, https://babele.co/\#!/projects) and case-related insights (Asknature, https://asknature.org/about-asknature/the-asknature-story/).

Ecosmes.net platform includes user-friendly and free-of-charge services and tools that support all phases of the product eco-innovation process in small and medium-sized enterprises (SMEs). This web-based platform is developed in multi-languages and tailored to each national context. According to Buttol et al. (2012) "all information, methods, and tools need by SMEs to start, develop and bring an ecoinnovation process are implemented such as: environmental information and downloadable documents concerning eco-innovation policies, regulations and tools, simplified LCA and eco-design tools, training courses targeted at SME technicians and consultants" as illustrated in Figure 1. Two simplified tools (eVerdEE for screening LCA and TESPI for supporting the environmentally conscious design) are implemented to support the analysis of the product/ processes and the product (re)design accordingly.

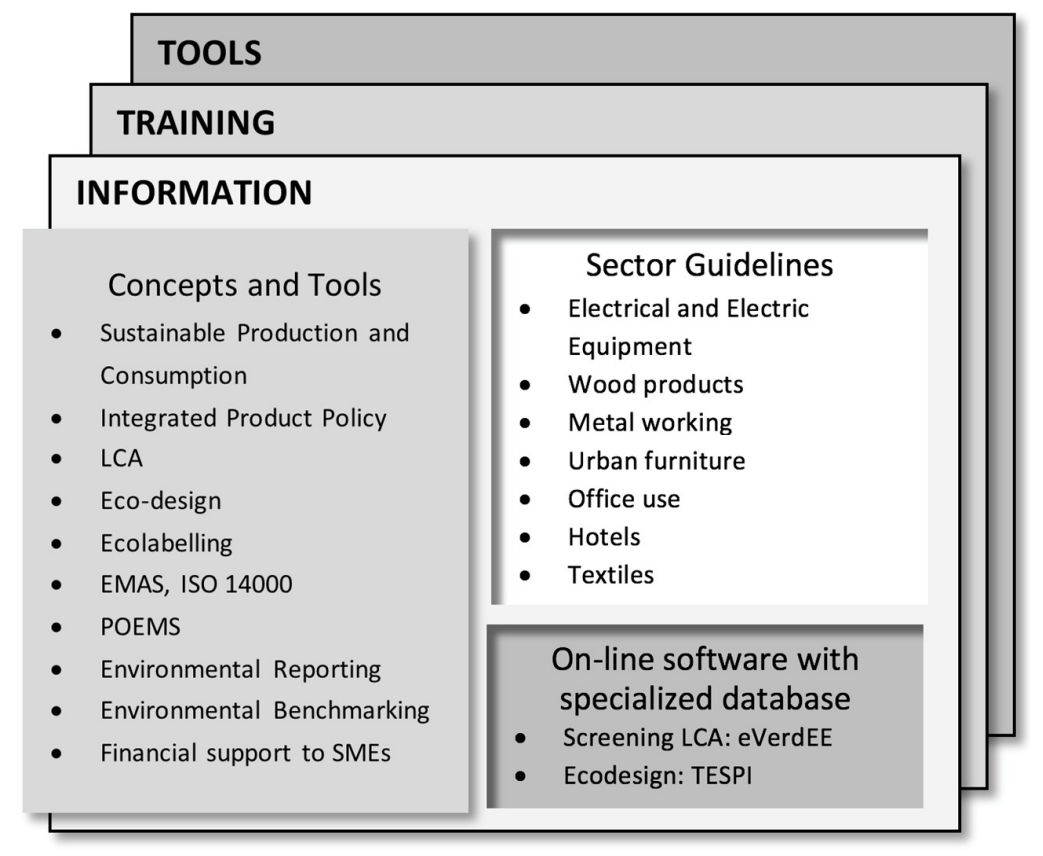

Figure 1. Ecosmes.net content structure (Buttol et al., 2012)

Ecosmes.net has successfully provided a customized solution supporting product eco-innovation of SMEs. However, the web-based platform need to be enhanced with new navigation methods and 
visualisations tools. Many hyperlinks are embedded in standard HTML pages lead. This representation approach takes a lot of time to navigate among resources and limits perception capacities of users.

Babele (https://babele.co/\#!/projects) social innovation platform provides a network of communities that can interact with each other: social innovation actors, entrepreneurs, incubators, universities, citizen. Though this crowd-mentoring and peer-learning approach, the Babele platform aims to "enable experts and ordinary citizens to take an active role in developing solutions for the greater good by supporting social enterprises form all-over the world to build viable and sustainable business models". Up to now, there are 30 communities, nearly 10000 users and over 750 projects available on the Babele platform. Each project is well presented in five different categories: Overview, Business Model, Discussions, Resources and Network. Users can leave their comments, suggestions or questions about the content of each category. Figure 2 presents a screenshot of a Business Models' description containing a problem description, vision \& mission, goals, social impacts, needs and challenges. It includes also extra information such as customers segments, value proposition, revue model, marketing strategy as well as key resources, stakeholders, financial plan.

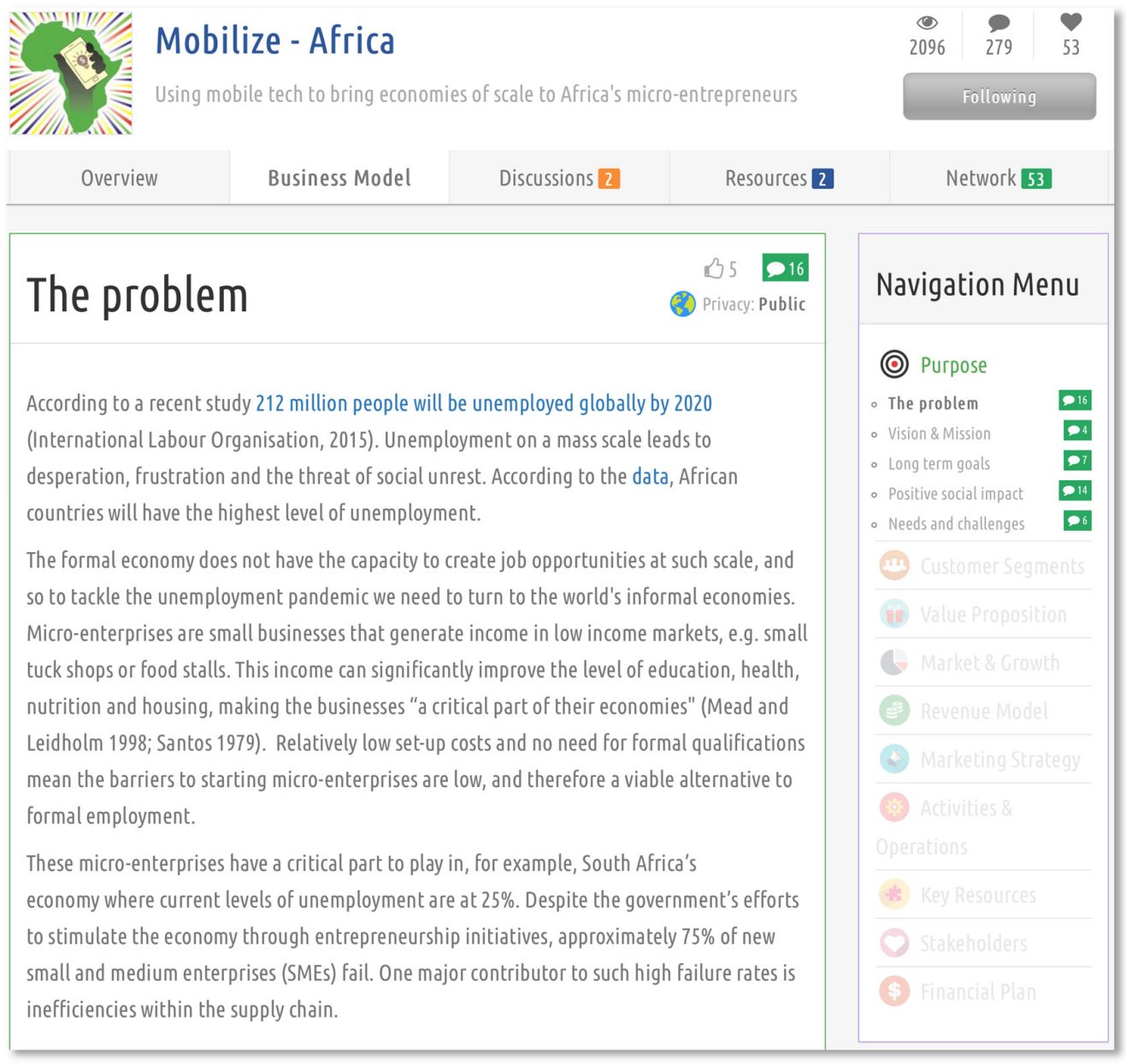

\section{Figure 2. Screenshot of project's business model description on Babele platform (https://babele.co/\#!/projects)}

The Babele platform has successfully attracted a huge number of users coming from various disciplines with various backgrounds. By combining the creative and intellectual capacities of these highly diverse users, the platform provides a powerful tool to produce optimal solution to complex issues in social innovation. However, some visualisation tools should be integrated in the platform to improve the exploration of projects and to highlight all eventual relationships among them. 
Asknature.org (http://asknature.org) (Vandevenne et al., 2012) is a biomimetic-inspired platform that is highly recognized in the research community. The Asknature.org platform links biological functions/ strategies with living systems with the main aim is to "help designers, entrepreneurs, architects, engineers, and other non-biologist innovators find inspiration from biological structures, processes and systems that already thrive in balance with Earth's complex systems". Asknature.org seeks to inspire users with biological information relevant to their service or product design challenges. Information available on this platform are classified into four categories: Biological strategies, inspired ideas, resources and collections. Once an innovator formulates their design challenge according to function in the Biomimicry Taxonomy (https://asknature.org/resource/biomimicry-taxonomy/), the platform helps to expose an array of strategies that biological systems developed to achieve those functions.

Like the Babele platform, the limitation of the Asknature.org is the lack of visualisation tools (intuitive and visual representation) that are very useful for the exploration of information like biological strategies or inspired strategies.

We present in the next section our proposed platform that support the eco-innovation process from the ideas generation phase (eco-ideation) with the help of seven Eco-Ideation Stimulation Mechanisms (ESMs) (Tyl et al., 2017) and a selected set of eco-innovation cases (Vallet et al., 2017).

\section{ALIENNOR - a supported platform for eco-innovation}

\subsection{Sevens ESMs and database of eco-innovation cases}

The success of idea generation phase depends on the ability of socio-economic actors to open up new perspectives, to seek a new point of view by breaking down the established framework of the problem, and thus to put into perspective alternatives and new situations. This ability to open new perspectives requires the setting up of stimulation mechanisms that help design teams to distort their usual reasoning. However, current eco-innovation tools are often focused on evaluation phases, leaving the generation phase and especially the maturation of ideas. In addition, traditional stimulation mechanisms appear to be ill-relevant to environmental issues. Indeed, they propose either "macro-mechanisms", i.e. generic stimulation mechanisms but with a too general vision of the problem; either "micro-mechanisms" focused on limited technical approaches and not supporting the maturation process, as proposed by TRIZ adaptations for eco-innovation (Yang and Chen, 2011). The ALIENNOR project introduces the original use of "meso-mechanisms" that allows to have a systemic vision of the problem, while effectively stimulating the project group and acting on the development cycle of ideas (generation, maturation, acceptance).

From 300 to 500 eco-innovation cases are studied. This proven case density is necessary to legitimize eco-ideation mechanisms to eco-innovate by covering the different business configuration and environmental problems that may exist. Eco-innovation cases integrated in the ALIENNOR platform are identified from various sources, among which a free database (http://www.efficycle.fr) scrutinizing sustainable news and projects.

\subsection{ALIENNOR platform proposition}

\subsubsection{Main aims of the ALIENNOR platform}

The most important aim of the ALIENNOR platform is to provide a supportive platform that originally combines methodological inputs on eco-innovation, case-based inspirations and network-based representations (see for instance in (Parraguez and Maier, 2016)), with expected usability performances for different types of users such as experts, students, SMEs (see Figure 3). The second aim of the ALIENNOR is to test and validate the use and the feasibility of seven ESMs proposed by ALIENNOR project partners. Thanks to implemented functions (navigation, filters, visualization), users can not only more understand about EMSs and Eco-innovation cases but also enrich and complete them. Seven proposed ESMs are used mainly in the ideation phase of the eco-innovation process; but only two or three of them should be used in a particular ideation phase. The third aim of the ALIENNOR platform is then to facilitate the identification of these most relevant ESMs. This third aim is not addressed in the scope of this article. 


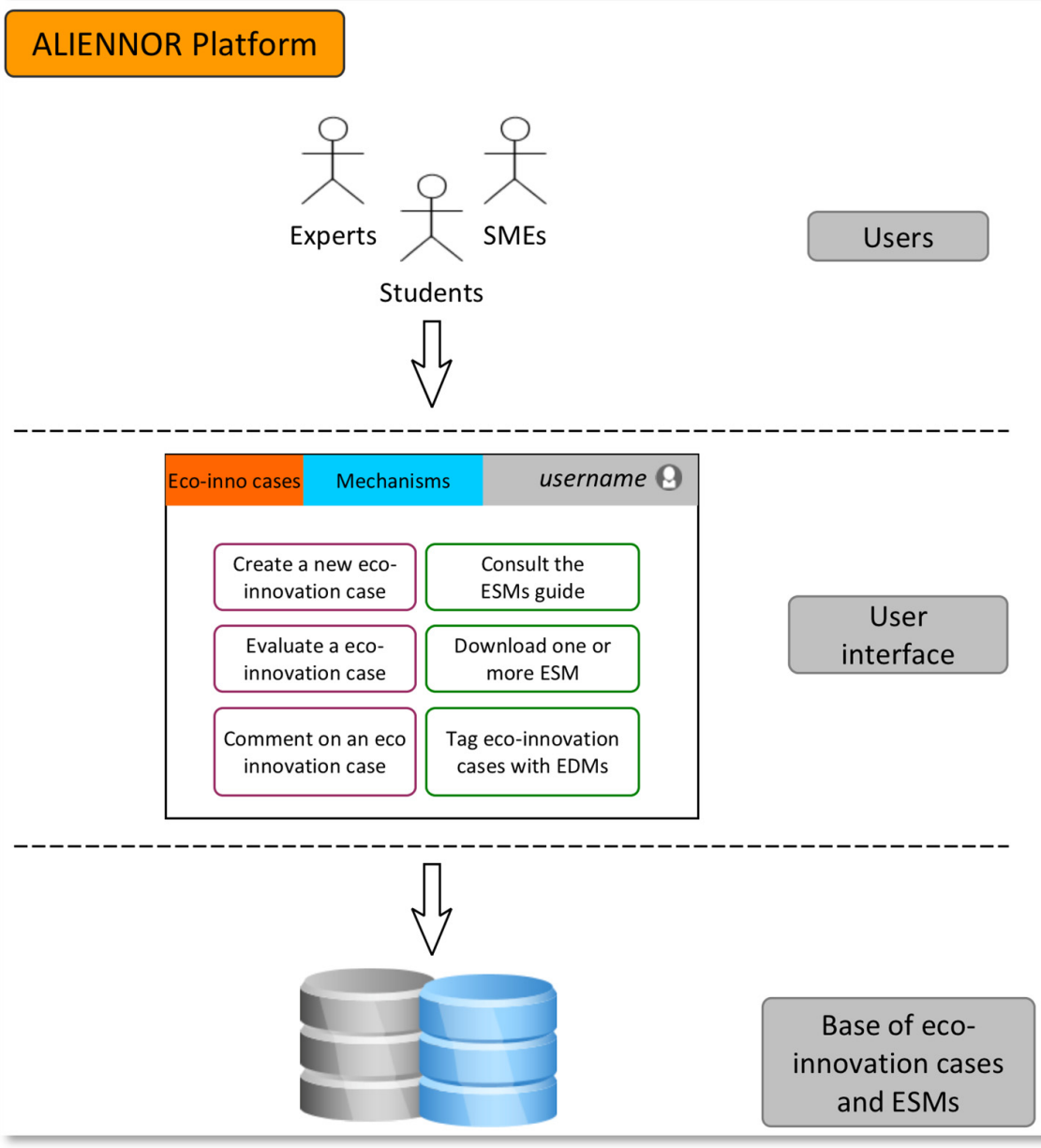

Figure 3. An oriented users' backgrounds / profiles platform

To archive these aims, the ALIENNOR platform proposes an integration of seven EMSs and a rich base eco-innovation cases, as well as appropriate functions allowing the creation and the animation of a community that helps to promote the product eco-innovation. In this community, three kinds of users are identified: Experts (eco-innovation researchers and ALIENNOR project members); SMEs and startups; and students (Figure 3).

\subsubsection{Two platform modules}

Functions implemented in the ALIENNOR platform are classified into two main modules:

- Methodology module: Allows the definition of eco-innovation project, the dynamic integration of ESM choice matrix and its use, access to relevant eco-innovation cases, the integration and support to the maturation of ideas generated, the evaluation of their sustainability

- Community module: Enables the creation of a community of SMEs willing to explore new concepts of eco-innovation. This community offers opportunities to shape feedback, which will enrich the base of eco-innovation cases and good practices concerning proposed tools and methods. It could also allow the constitution of a consortium with complementary skills, to allow the emergence of new business models associated with eco-innovations.

\subsubsection{Principal scenarios}

Potential users of the ALIENNOR platform are project researchers, SMEs and start-ups, students and members of EcoSD (http://www.ecosd.fr/en/) association. Belong to the backgrounds of each kind of users, three main scenarios the platform are identified (Figure 4): 


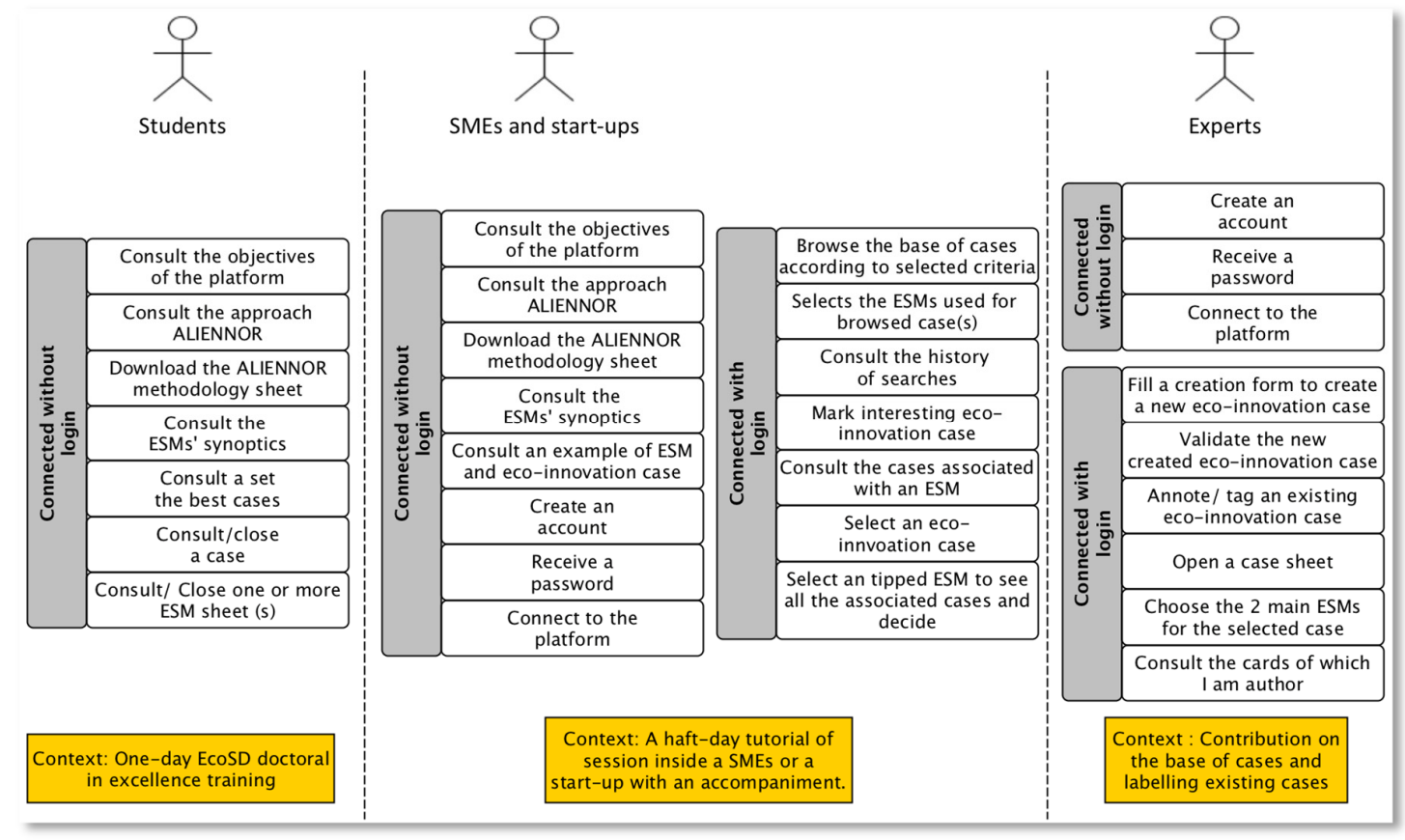

Figure 4. User's action flows on the ALIENNOR platform

- Scenario 01 (for students): The platform is used in one-day eco-innovation training leading by one or some professors. In this target, students understand what, why and how ESMs are constructed. They can also explore a best of eco-innovations cases with full description and their corresponding tagged ESMs.

- Scenario 02 (for SMEs and start-ups): A haft-day tutorial of session inside a SMEs or a start-up with an accompaniment. From an eco-innovation brief, some questions are raises such as: How to select adapted SMEs in groups? How to draw inspiration from existing eco-innovation cases? How to formalize the generated concepts after applying the ESMs. For this purpose, the industrial practitioners can consult from 50 cases in the database with navigation and filtering tools. They can visualize all the relations between eco-innovation cases and their associated EMSs in a graphbase representation. Users can see the history of searches and mark eco-innovation cases that they are interested in.

- Scenario 03 (for project researchers): This scenario is dedicated to experts who have a solid understanding about the ALIENNOR methodology. They can also create new eco-innovation cases and identify corresponding appropriate ESMs.

\subsection{Development of the ALIENNOR platform}

The development has been developed from the beginning of the last year of the project. Main platform's roles and corresponding scenarios are therefore identified before, through many group work sessions between project's members and eco-innovation scientists. The first step of the platform's development is then to establish specifications of the platform. Due to our experiences archived in previous projects, to have an easy and optimal usability (notably for scientists and SMEs), a web-based platform with appropriate navigation and visualization techniques is the most promising solution. A web-based platform also allows users at geographically distributed locations to work together.

The ALIENNOR web platform is developed using the newest web technologies (Angular 2 for Frontend and Django Rest Framework for Backend). For the purpose of test, $\mathbf{5 0}$ eco-innovation cases (summarized by category in Table 1), carefully selected from 400 eco-innovation cases (as mentioned above), have been integrated along with seven ESMs. Each case is presented in a form composing of 10 different champs (as illustrated in Figure 5): Visualization (case's images), Promise (short description of case's functions, values), Usage (detail description about case), Organization (product's components, 
components' materials, etc.), Economic transaction (economic values of product), Evaluation (user's evaluations such as environmental gains), Associated ESMs. Users are free to add new eco-innovation cases into the database through a dedicated form. This creation form includes also an image field that allows users to upload one or many images and attach them to the new case. Instead of creating one by one a new case with the creation form, users can also import many cases in the same time into the database from ".json" or ".csv" files.

Table 1. Summary by category of 50 currently implemented cases in the platform ALIENNOR (non-exhaustive)

\begin{tabular}{|c|l|}
\hline \multicolumn{2}{|l|}{ Clothes - Textile (4) } \\
\hline 28 & Worn Again, procédé de recyclage textile basé sur séparation polyester-coton \\
\hline 175 & MUD Jeans ou le leasing de jeans \\
\hline 287 & Hopaal fabrique des tee-shirts avec des déchets recyclés \\
\hline 297 & Vêtements durables et garantis 30 ans \\
\hline Energy (8) \\
\hline 5 & Fermentalg le pétrole vert avec des micro-algues \\
\hline 10 & hydroélectricité grâce à l'eau des canalisations \\
\hline 66 & "Windstalk», pour produire de l'électricité avec des roseaux géants \\
\hline 76 & Eolienne à effet vibratoire \\
\hline 79 & PowerWindows, revêtement de fenêtre solaire \\
\hline 85 & Twido, chauffe-eau intelligent ! \\
\hline 108 & Maison active qui produit 2 fois plus d'énergie qu'elle n'en consomme ! \\
\hline 109 & "Chaudière numérique" qui recycle la chaleur des serveurs informatiques \\
\hline Food (4) \\
\hline 138 & Food Tuner : des idées de recettes avec les ingrédients à disposition \\
\hline 240 & Serre verticale au sein du supermarché \\
\hline 48 & Une date de péremption tactile anti-gaspillage alimentaire \\
\hline 263 & Drive mettant l'alimentation locale à portée de clic \\
\hline
\end{tabular}

\begin{tabular}{|c|l|}
\hline \multicolumn{2}{|l|}{ Sustainable Conso Mode (10) } \\
\hline 2 & Back Market, vendeur d'appareils reconditionnés \\
\hline 17 & SHAREVOISINS, la solution de partage pratique entre voisins! \\
\hline 40 & Scio pour connaître la composition de tout ce qui nous entoure \\
\hline 46 & Bio-ECLAIRAGE (Glowee) \\
\hline 63 & Empruntez-le.fr, le site de prêt d'objets de coups de mains \\
\hline 71 & TERRABILIS, le Monopoly écolo, bientôt adapté en jeu vidéo \\
\hline 116 & Des mégots pour bulletins de vote \\
\hline 167 & CROWDTIMING, ou mobiliser du temps ! \\
\hline 184 & Compost challenge, pour apprendre à trier ses déchets et gérer un composteur \\
\hline 279 & Boutique de produits garantis à vie vs l'obsolescence programmée \\
\hline Equipment (7) \\
\hline 53 & Drumi, la machine à laver à pédales \\
\hline 67 & Du plastique recyclé dans des bobines de filament pour imprimantes 3D \\
\hline 83 & Ecocup, les gobelets réutilisables jusqu'à 100 fois \\
\hline 151 & L'increvable, lave-linge conçu pour au moins 50 ans \\
\hline 201 & Frigo 100\% écolo, sans électricité ! \\
\hline 258 & Greenspector, logiciel pour réduire l'impact énergétique des logiciels \\
\hline 293 & Pièces détachées imprimables en 3D (par distributeur Boulanger) \\
\hline
\end{tabular}

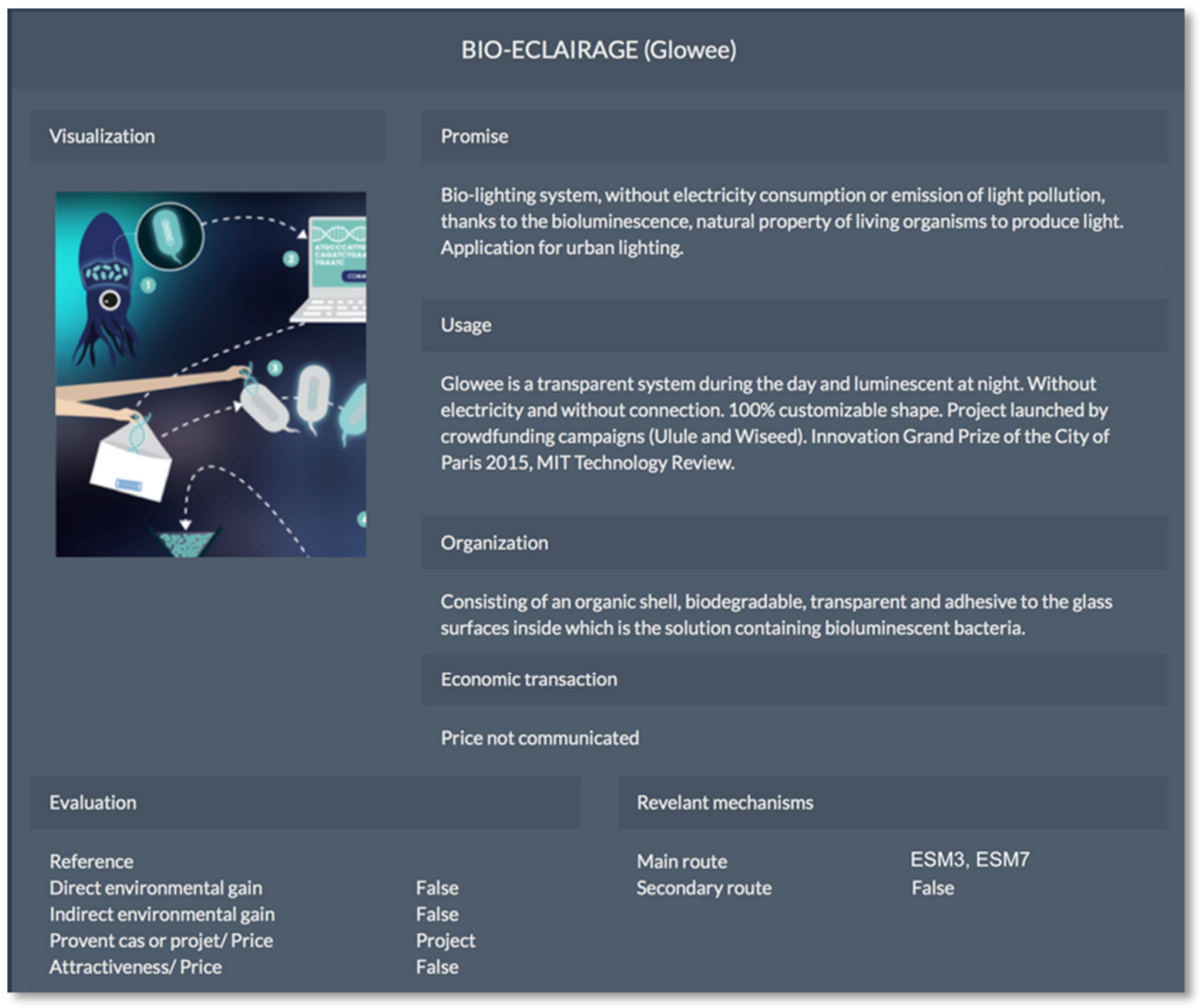

Figure 5. Representation of an eco-innovation case on the ALIENNOR platform 
In the "Methodology module", providing users an overview of ALIENNOR methods and seven ESMs is essential. As illustrated in Figure 6, each ESM representation contains a detailed description of all ESM's component (characterization of initial state of system, identification of significant parameters, generation of ideas). User can download a ".pdf" file of this description for further consultation or display all eco-innovation cases associated to the currently selected ESM.

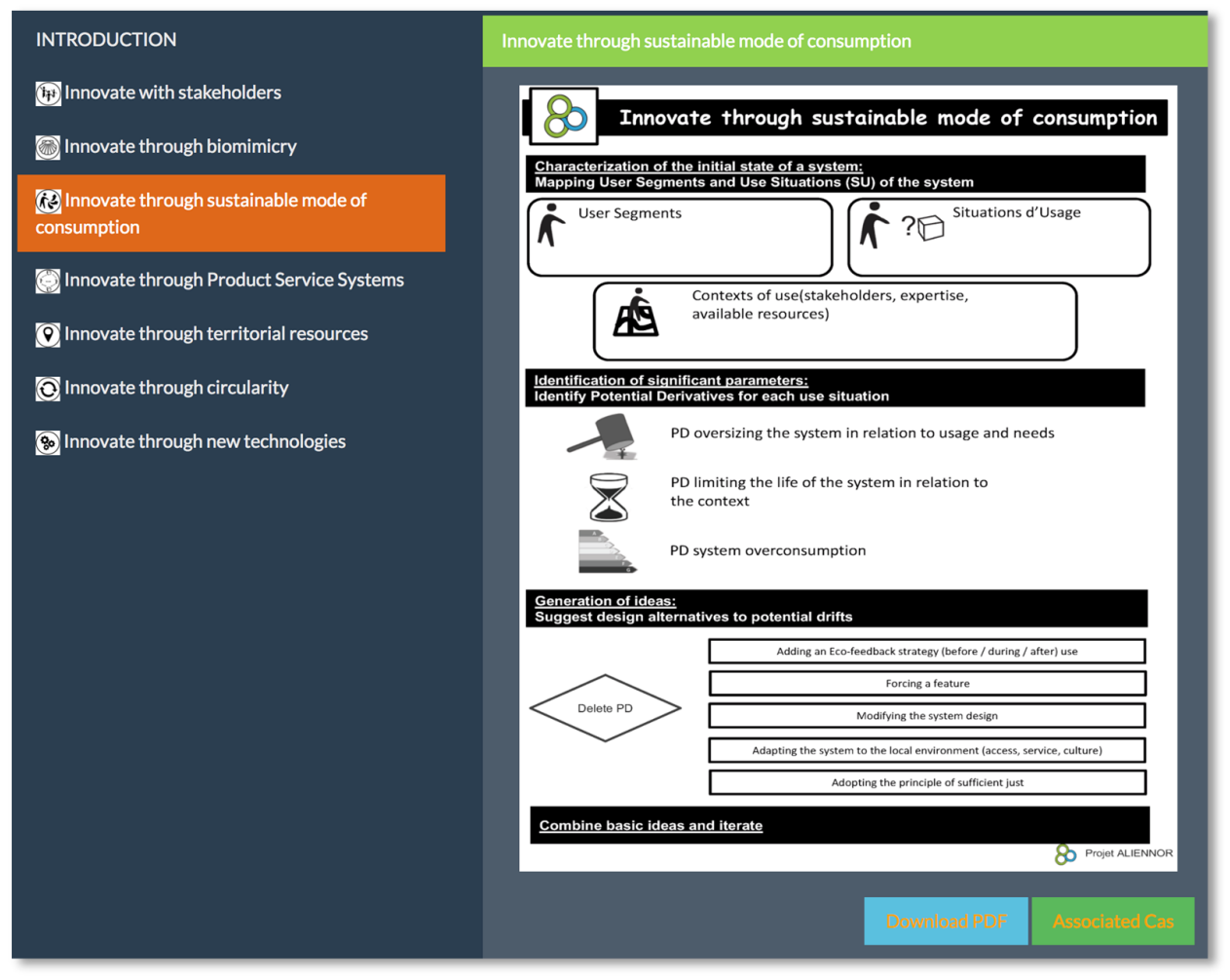

Figure 6. Representation of an eco-innovation case on the ALIENNOR platform

An essential mission of the ALIENNOR platform is to provide to all users an efficient exploitation of the base of innovation-cases and their links with ESMs. At the current version, we provide two kinds of visualisation:

- Visualisation of eco-innovation cases related to each ESM: All eco-innovation cases related to the ESM are represented as a circle named by case's name around the centred node that represent the EMS (Figure 7).

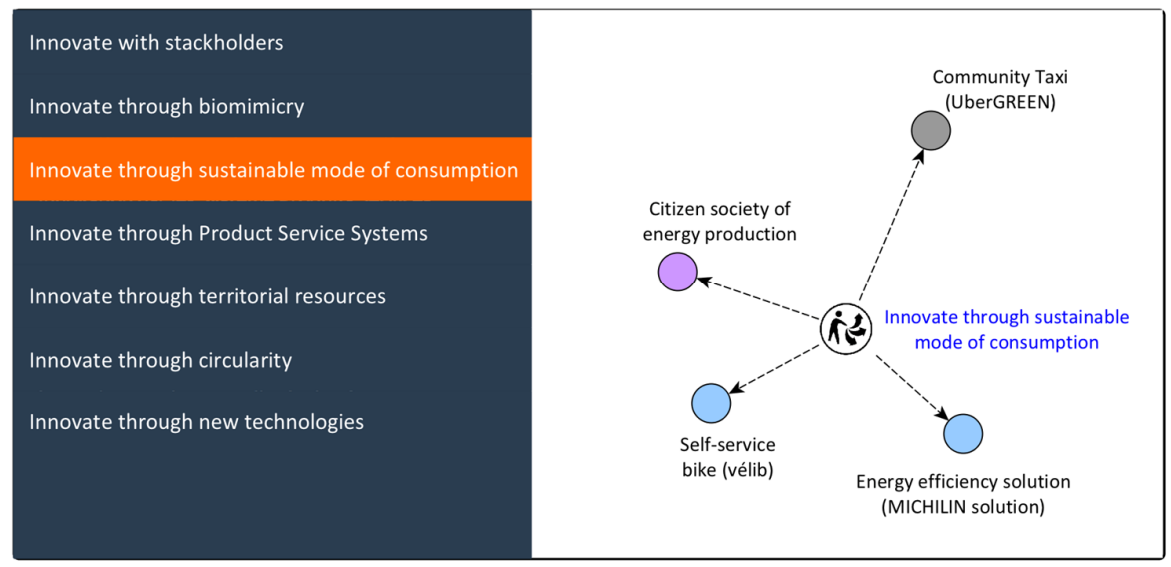

Figure 7. Visualisation of eco-innovation cases related to each ESM 
- Visualisation of EMSs related to each eco-innovation cases: Seven EMSs are represented in a circle whose centre is the eco-innovation case. Each EMS is represented by a circle whose diameter is proportional to its degree of correlation with eco-innovation case (Figure 8).

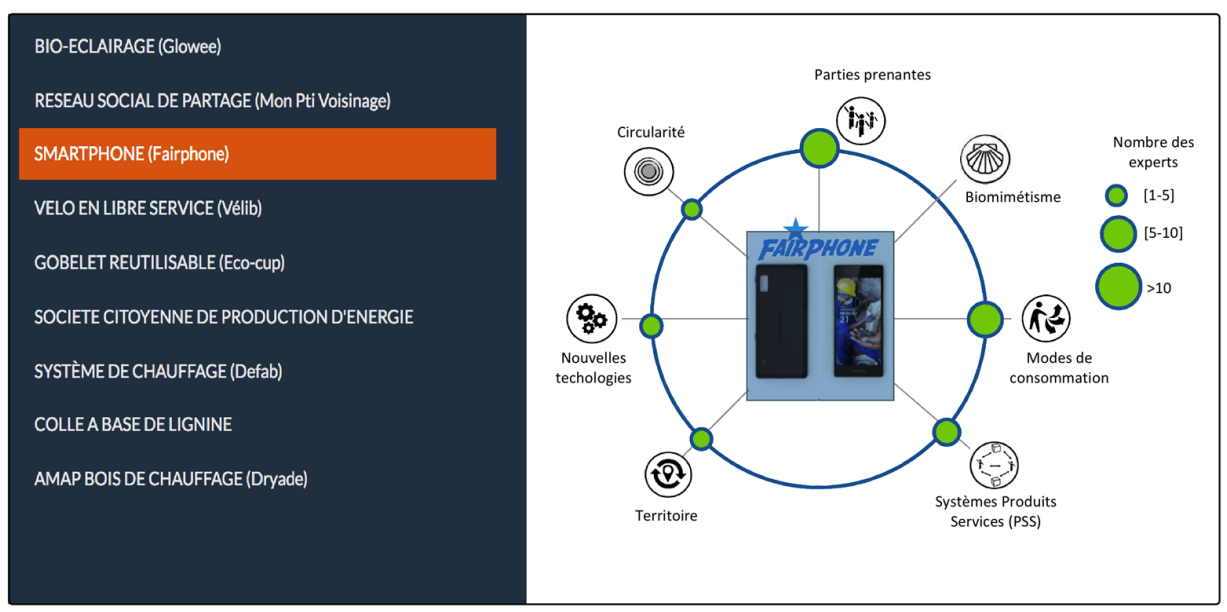

Figure 8. Visualisation of EMSs related to each eco-innovation cases

\subsection{Discussion}

The current version of platform focuses mainly in the "Methodology module" that helps to assimilate the understanding about ESMs and the exploration of best eco-innovative cases. It allows also to create and to tag eco-innovation cases with two or three adapted EMSs in a simple and intuitive way. We believe strongly visual representations of an eco-innovation case with its related EMSs or a EMS with all associated eco-innovation cases are a promising approach to maximally explore them, and then promote the eco-innovation.

The remain development work falls into the "Community module" that aims to bring a collaboration environment for experts to exchange, evaluate and enhance the base of eco-innovation cases as well as to improve the usability of seven proposed ESMs.

\section{Conclusion and perspectives}

Eco-innovation still remains an ill-defined concept and ambiguous for industrial practitioners. Its lack efficient supportive tools and methods, especially at the idea generation phase (eco-ideation). Most current eco-ideation tools are based of "macro" or "micro" mechanisms. Within project ALIENNOR, seven ESMs have been proposed to help designers to generate new valuable eco-innovative ideas.

This paper presents our original contribution, the ALIENNOR platform as a supportive platform that combines methodological inputs on eco-innovation, case-based inspirations (CBR) and network-based representations. The proposed platform contains a "Methodology module" including functions to test and validate seven proposed ESMs and a "Community module" to enrich the base of eco-innovation cases as well as to enhance the ESMs. We recommend strongly using visualisation methods/ tools to improve the exploration of eco-innovation cases and their relationships with corresponding mechanisms. As perspective, a voting rules on ESMs should be implemented. This function allows users to grade the correlation between an eco-innovation case and an ESM. The most appropriate ESMs could be deduced from the voting results.

Lastly, in addition to the web-based version, the platform should also be developed on mobile-devices to attract more and more users. This implementation also provides a more convenient way to enrich the base of eco-innovation cases by facilitating the creation of new cases.

\section{Acknowledgement}

The authors wish to thank the French National Research Agency (ANR) for its funding of the ALIENNOR project (project reference: ANR-15-CE10-0001). 


\section{References}

Bocken, N., Short, S., Rana, P. and Evans, S. (2013), "A value mapping tool for sustainable business modelling”, Corporate Governance: The International Journal of Business in Society, Vol. 13 No. 5, pp. $482-497$. https://doi.org/10.1108/CG-06-2013-0078

Bocken, N.M.P., Allwood, J.M., Willey, A.R. and King, J.M.H. (2011), "Development of an eco-ideation tool to identify stepwise greenhouse gas emissions reduction options for consumer goods", Journal of Cleaner Production, Vol. 19 No. 12, pp. 1279-1287. https://doi.org/10.1016/j.jclepro.2011.04.009

Brezet, H. (1997), Ecodesign, a promising approach to sustainable production and consumption, United Nations Environmental Program (UNEP).

Buttol, P., Buonamici, R., Naldesi, L., Rinaldi, C., Zamagni, A. and Masoni, P. (2012), "Integrating services and tools in an ICT platform to support eco-innovation in SMEs", Clean Technologies and Environmental Policy, Vol. 14 No. 2, pp. 211-221. https://doi.org/10.1007/s10098-011-0388-7

Buzuku, S. and Shnai, I. (2018), “A systematic literature review of TRIZ used in Eco-Design”, Journal of the European TRIZ Association, Vol. 4, pp. 20-31.

Fussier, C. and James, P. (1996), Driving Eco-Innovation: A Breakthrough Discipline for Innovation and Sustainability, Pitman, London.

Parraguez, P. and Maier, A. (2016), "Network Insights for Partner Selection in Inter-organisational New Product Development Projects", Proceedings of the DESIGN 2016 / 14th International Design Conference, Dubrovnik, Croatia, May 16-19, 2016, The Design Society, Glasgow, pp. 1095-1104.

Real, M. (2015), How to support the maturation of eco-innovative concepts?: proposition of the method MIRAS to overcome collective lock-ins and explore stakeholder networks, $\mathrm{PhD}$ thesis, Université de Bordeaux.

Russo, D., Bersano, G., Birolini, V. and Uhl, R. (2011), "European testing of the efficiency of TRIZ in ecoinnovation projects for manufacturing SMEs", Procedia Engineering, Vol. 9, pp. 157-171. https://doi.org/10.1016/j.proeng.2011.03.109

Russo, D., Schöfer, M. and Bersano, G. (2015), "Supporting ECO-innovation in SMEs by TRIZ Eco-guidelines", Procedia Engineering, Vol. 131, pp. 831-839. https://doi.org/10.1016/j.proeng.2015.12.388

Tyl, B., Legardeur, J., Millet, D. and Vallet, F. (2014), “A comparative study of ideation mechanisms used in ecoinnovation tools", Journal of Engineering Design, Vol. 25, No. 10-12, pp. 325-345. https://doi.org/10.1080/09544828.2014.992772

Tyl, B., Pialot, O., Vallet, F. and Millet, D. (2017), Éco-innover à l'aide de méso Mécanismes de Stimulation d'Éco-idéation (MSE). [online] Available at: https://www.techniques-ingenieur.fr/basedocumentaire/innovation-th10/eco-conception-concepts-et-methodes-42566210/eco-innover-a-l-aide-demeso-mecanismes-de-stimulation-d-eco-ideation-mse-ag6785/ (accessed 12.11.2017).

Tyl, B., Vallet, F., Pialot, O., Millet, D., Le Duigou, J. and Graves, G. (2016), “The ESM approach: 8 mechanisms to efficiently support eco-ideation", Proceedings of the DESIGN 2016 / 14th International Design Conference, Dubrovnik, Croatia, May 16-19, 2016, The Design Society, Glasgow.

Vallet, F., Tyl, B., Pialot, O. and Millet, D. (2017), "Is this system eco-innovative? A case-based workshop", Proceedings of ICED'17 / The 21st International Conference on Engineering Design, Vancouver, Canada, August 21-25, 2017, The Design Society, Glasgow.

Vandevenne, D., Verhaegen, P.-A., Dewulf, S. and Duflou, J. (2012), "Automated classification into the Biomimicry Taxonomy”, Proceedings of DESIGN 2012 / 12th International Design Conference, Dubrovnik, Croatia.

Yang, C.J. and Chen, J.L. (2011), "Accelerating preliminary eco-innovation design for products that integrates case-based reasoning and TRIZ method", Journal of Cleaner Production, Vol. 19 No. 9-10, pp. 998-1006. https://doi.org/10.1016/j.jclepro.2011.01.014

Dr.-Ing. Cong Cuong Pham, Post-doctorant

University of Technology of Compiègne, Mechanical Engineering

Rue du docteur Schweitzer, 60200 Compiègne, France

Email: phamcong@utc.fr 